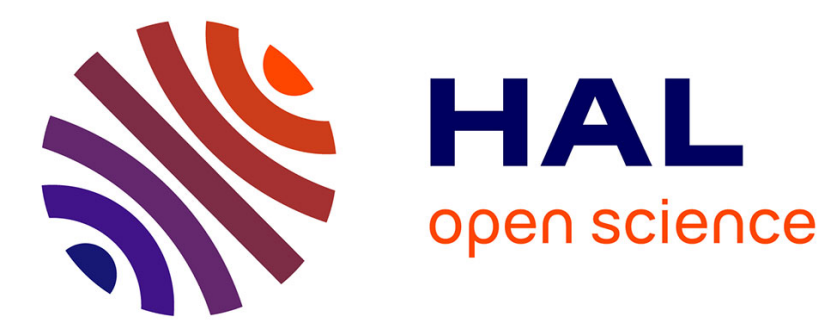

\title{
Induction chemotherapy in head and neck cancers: Results and controversies
}

Max Gau, Andy Karabajakian, Thibaut Reverdy, Eve-Marie Neidhardt, Jérôme Fayette

\section{To cite this version:}

Max Gau, Andy Karabajakian, Thibaut Reverdy, Eve-Marie Neidhardt, Jérôme Fayette. Induction chemotherapy in head and neck cancers: Results and controversies. Oral Oncology, 2019, 95, pp.164 - 169. 10.1016/j.oraloncology.2019.06.015 . hal-03484925

\section{HAL Id: hal-03484925 \\ https://hal.science/hal-03484925}

Submitted on 20 Dec 2021

HAL is a multi-disciplinary open access archive for the deposit and dissemination of scientific research documents, whether they are published or not. The documents may come from teaching and research institutions in France or abroad, or from public or private research centers.
L'archive ouverte pluridisciplinaire HAL, est destinée au dépôt et à la diffusion de documents scientifiques de niveau recherche, publiés ou non, émanant des établissements d'enseignement et de recherche français ou étrangers, des laboratoires publics ou privés.

\section{다)(1) $(5$}

Distributed under a Creative Commons Attribution - NonCommerciall 4.0 International 


\section{INDUCTION CHEMOTHERAPY IN HEAD AND NECK}

\section{CANCERS: RESULTS AND CONTROVERSIES}

Max Gaua, Andy Karabajakianª, Thibaut Reverdya, Eve-Marie Neidhardt MD PhDa, Jérôme Fayette MD PhDa

aCentre de Lutte Contre le Cancer Léon Bérard, Lyon-I University, Lyon, France

Corresponding author:

Jérôme Fayette

Email : jerome.fayette@lyon.unicancer.fr

Phone: +334 78785103

Fax : +33478 782716

Medical Oncology Department, Centre de Lutte Contre le Cancer Léon Bérard

69008 Lyon, France 


\section{ABSTRACT:}

Standard treatment for locally advanced head and neck squamous cell carcinoma (LAHNSCC) consists mainly of concurrent chemoradiation (CCR) but induction chemotherapy (IC) by docetaxel-cisplatin-fluorouracil (TPF), followed by CCR, is a strong option. Comparative trials suggest that IC and CCR are equivalent, and some trials suggest superiority of IC, whereas none shows inferiority. IC might have less interest in oropharyngeal cancer (more often linked to HPV infection). When functional laryngeal preservation is the patient's priority, essays strongly suggest that IC is the best treatment. There is little data about a less toxic regimen of IC, but several schemes are promising and need to be developed. An early selection of responders to IC by metabolic imaging must be considered. Intensification attempts with cetuximab were too toxic and unsafe, but trials with immunotherapy are ongoing to enhance TPF efficacy. After IC, CCR either with cetuximab or cisplatin seems to be equally effective.

Key words: head and neck cancer, induction chemotherapy, locally advanced, chemoradiation, organ preservation 


\section{1 | INTRODUCTION:}

Head and neck squamous cell carcinoma (HNSCC) is the sixth most common cancer worldwide, with over 650,000 new diagnoses every year[1]. HNSCC are locally advanced (T3, T4 or N+, LAHNSCC) in $60 \%$ of newly diagnosed patients. For resectable disease, concomitant chemoradiation (CCR) and surgery followed by radio(chemotherapy) are both effective. The choice of treatment depends largely on the tumor's localization and the schools. For inoperable diseases, CCR remains the standard but induction chemotherapy (IC) followed by surgery and/or CCR is a strong option. In this review we will focus on IC: rational, type, results, controversies and future directions.

\section{2 | RATIONAL AND STANDARD INDUCTION:}

Induction chemotherapy can eradicate micro metastases and thus increase progression free survival (PFS) and overall survival (OS) in patients with LAHNSCC. It can predict the tumor's sensitivity and can help decide between radical surgery and CCR[2], even if this assumption lacks definitive proof. Indeed, of the 24 out of 173 patients with laryngeal cancer who did not respond to IC in the RTOG 91-11[3] (detailed later), 11 were cured by radiotherapy, and in a retrospective study there did not seem to be a difference in OS or PFS between patients who refused total laryngectomy after no response to IC and those who had radical surgery before radiotherapy[4]. Finally, IC can decrease the tumor volume and make it operable when surgery was formerly too risky or too mutilating, in order to enhance quality of life.

The MACH-NC meta-analysis showed a significant benefit of IC if cisplatin and fluorouracil were used [5] and for more than 30 years, standard treatment for IC was cisplatin $100 \mathrm{mg} / \mathrm{m}^{2}$ 
(on day one) and fluorouracil $1000 \mathrm{mg} / \mathrm{m}^{2}$ per day, administered as a continuous $24 \mathrm{~h}$ infusion for five days, every three weeks (PF).

Since paclitaxel and docetaxel demonstrated activity, they have been included in induction chemotherapy regimens. Two phase III trials compared docetaxel $75 \mathrm{mg} / \mathrm{m}^{2}+$ cisplatin $75 \mathrm{mg} / \mathrm{m}^{2}\left(\right.$ or $\left.100 \mathrm{mg} / \mathrm{m}^{2}\right)+$ fluorouracil $750 \mathrm{mg} / \mathrm{m}^{2} / \mathrm{d}$ for five days (TPF) versus PF every three weeks in HNSCC: TPF increased PFS (11.0 months versus 8.2 months; $p=0.007$ in the first study with unresectable tumors and 38 months vs $13.2 ; \mathrm{p}=0.011$ in the second one with resectable and unresectable tumors) and OS (18,8 months vs $14.5 ; \mathrm{p}=0.02$ and 71 months vs 35; $\mathrm{p}=0.014$ ) [6-8]. Moreover, due to lower doses of cisplatin and fluorouracil in the TPF scheme, severe adverse events were less frequent in the TPF group than in the PF group. A meta-analysis of five randomized trials with 1,772 patients showed that TPF (with paclitaxel or docetaxel) was associated with significant reductions of progression, locoregional failure, and distant failure if compared with PF [9]. The hazard ratio of death was 0.79 (95\% CI 0.70 to $0.89 ; \mathrm{p}<0.001$; absolute benefit at 5 years: $7.4 \%$ ). So, when induction is considered, the standard treatment is TPF.

\section{3 | A GOLD STANDARD FOR LARYNX PRESERVATION?}

Figure A: 10-year results of EORTC trial for larynx preservation.

Figure B: 10-year results of RTOG 91-11 trial for larynx preservation.

Total laryngectomy cures advanced hypopharynx or larynx cancer but is mutilating. In 1991, a study demonstrated that three cycles of PF followed by radiotherapy allowed a survival rate similar to total laryngectomy (2-year survival of $68 \%$ in both groups, $\mathrm{p}=0.9846$ ), with more frequent local recurrences and fewer distant metastases [10]. Larynx was preserved in $64 \%$ of 
the patients treated by IC. A European study confirmed equivalent results with surgery and IC in hypopharyngeal squamous cell carcinomas with a 10 -year survival rate of $13.8 \%$ and $13.1 \%$ respectively [11]. In the IC arm, the 10-year survival rate with a functional larynx was $8.7 \%$.

The RTOG 91-11 trial compared CCR with cisplatin q3w and RT alone with the induction PF approach in 520 patients with stage III or IV glottic or supraglottic cancer. High-volume T4 (primary invasion $>1 \mathrm{~cm}$ into the base of tongue or penetration through cartilage) were excluded. The long-term results showed that CCR significantly improved the larynx preservation rate over IC followed by RT (HR 0.58; $95 \%$ CI 0.37 to $0.89 ; \mathrm{p}=0.0050$ ) and over RT alone $(\mathrm{p}<0.001)$ [12]. However, there was a trend, although not significant, concerning laryngectomy-free survival with $28.9 \%$ at 10 years for the induction approach versus $23.5 \%$ for the concomitant approach. It was the same with OS, with 5- and 10-year estimates of 58\% and $39 \%$ for induction and $55 \%$ and $28 \%$ for concomitant, respectively. After about 4.5 years, the curves begin to separate, favoring induction, although the difference is not statistically significant. The increase of deaths in the CCR arm is not related to cancer deaths and could be related to intercurrent deaths due to a dysfunctional larynx (pneumonitis for example). The moderns radiation techniques could decrease this toxicity.

After the demonstration of superiority of TPF over PF as IC, this new scheme was studied. The GORTEC 200-2001 trial which compared induction by PF with TPF in 213 patients for organ preservation (stage III or IV larynx and hypopharynx) confirmed that TPF increased larynx-preservation and larynx dysfunction-free survival with possibly less toxicity [13]. The 5- and 10-year larynx dysfunction-free survival rates were respectively $74.0 \%$ (95\% CI 0.64 0.82 ) vs. $58.1 \%$ (95\%CI $0.47-0.68)$ and $70.3 \%$ (95\%CI $0.58-0.8)$ vs. $46.5 \%$ (95\% CI $0.31-$ 0.63, $\mathrm{p}=0.01$ ) in the TPF versus PF arm. Despite a trend for TPF, overall survival, disease- 
free survival, and locoregional control rates were not different, but TPF allowed significantly fewer grade 3-4 late toxicities of the larynx (9.3\% vs $17.1 \%, \mathrm{p}=0.038)$.

Those results were confirmed by the TAX324 trial for advanced hypopharyngeal and laryngeal cancers with an operable disease. Laryngectomy-free survival was significantly greater with TPF (HR: 0.59; 95\% CI: 0.37-0.95; P = 0.030)[14], with a strong trend in OS for TPF.

These trials strongly suggest that induction chemotherapy with TPF should be a standard of treatment for functional laryngeal preservation.

The definitive response will come from the GORTEC phase III study [15] that compares exclusive CCR with three cisplatin $100 \mathrm{mg} / \mathrm{m} 2$ to TPF followed by the same CCR.

\section{4 | INDUCTION FOR INOPERABLE PATIENTS OR FOR ORAL CAVITY AND OROPHARYNX CANCERS: RESULTS AND CONTROVERSIES:}

\section{1 | Direct comparisons in phase III trials}

Table 1: Direct comparisons in phase III trials

Standard treatment remains CCR and several phase III trials compared induction followed by CCR to exclusive CCR with discordant results.

Two American randomized phase III trials did not show any significant superiority of the IC + CCR strategy versus CCR alone [16, 17], but they are methodologically questionable. Indeed, they included only half of the planned patients (285/400 and 145/300) and the 
observed OS was higher than expected so the statistical power was too weak and could not lead to definitive conclusion. The only argument in favor of IC was the diminished metastatic failure in one of the trials[16]. Of note, in the DECIDE trial [16], there was a strong trend in OS in favor of IC in high-risk tumors (N2c and N3). This trend was also suggested in a retrospective analysis that showed a benefit in OS in favor of TPF vs CCR for high risk tumors (N2b, N2c and N3) with a not reached OS vs 14 months [18].

A French study randomized 370 inoperable patients, at least N2b, to receive exclusive CCR (70Gy potentiated by three cycles of carboplatin and fluorouracil) or IC followed by RT potentiated by cetuximab. In this population, the response rate was weak with induction (44.5\%) and $7 \%$ of toxic deaths were deplored during IC. Finally, there was no difference between the two arms with a 2-year PFS of $40 \%$ (less than the $45 \%$ expected for the control arm). Interestingly, survival without metastases was significantly better with induction (HR $0.62(\mathrm{IC} 95 \% 0.40-0.95) \mathrm{p}=0.03)[19]$.

A phase III Spanish trial [20] compared IC, either three TPF (155 patients) or three PF (156 patients), followed by CCR (potentiated by three cisplatin at $100 \mathrm{mg} / \mathrm{m}^{2}$ ) or the same exclusive CCR (128 patients). Out of 311 patients in the IC arms, only 220 (70\%) were irradiated. The reasons for that were: 13 deaths, 38 toxicities, 13 progressions, 27 other reasons. In the intent to treat analysis, no significant difference was observed between the three arms. But in the per-protocol analysis, the comparison of TPF + CCR versus CCR showed a significant benefit of IC + CCR for PFS (HR 0.72; 95\% CI 0.53-0.98; $\mathrm{p}=0.03$ ) with a non-significant trend for OS (35.6 months (95\% CI 24.2-51.4) vs 29.4 months (95\% CI 18.9-45.4). Even if we cannot exclude a lead time bias by selection of patients with a better prognosis, these results suggest that the sequential approach might offer better results for patients that can tolerate it. Of course, predictive markers are needed in order to determine which patients could respond to and tolerate IC before choosing the treatment's sequence. 
The last trial followed a phase II study that suggested benefit of IC followed by CCR vs CCR alone. It randomized 421 patients with stage III-IV HNSCC of the oral cavity, oropharynx and hypopharynx to one of four treatments: CCR (by cisplatin/fluorouracil two cycles), radiotherapy with cetuximab (CET/RT), three cycles of TPF followed by the same CCR or by CET/RT [21]. For analysis, data of the two IC arms and of the two exclusive RT were pooled. Results are significantly in favor of IC: complete response $42.5 \%$ vs $28 \%$ ( $\mathrm{p}=0.003$ ), median PFS 30.5 months vs 18.5 (HR 0.72; 95\%CI 0.56-0.93; p=0.013) and especially median OS 54.7 months vs 31.7 (HR 0.74; 95\%CI 0.56-0.97; $\mathrm{p}=0.031$ ), even in multivariate analysis. Since we cannot rule out in the exclusive arms that cetuximab is inferior to platin-based chemotherapy, we again cannot draw definitive conclusion, especially since in subgroup analysis there is no significant difference for patients treated only by platin-based chemotherapy and not cetuximab. Moreover the addition of the 101 patients of the phase II study in the phase III study could decrease the confidence in the statistical analysis. So, in direct comparisons, no study definitively concludes to the superiority of one strategy: IC seems non-inferior to exclusive CCR and remains a strong option. In all of these studies, it seems that induction has less interest in oropharyngeal cancer (more frequent in the American trials and more concerned by the HPV infection). Of note, for patients with high risk of metastases, IC could be a positive option.

\section{2 | Indirect comparisons by meta-analysis}

Several meta-analyses have been performed in order to demonstrate a potential difference between IC and CCR. Some demonstrated a significant lower metastasis rate of about 7\% [22, 23],[24] or a significant increase of PFS [25, 26] but none demonstrated any significant benefit in OS despite a trend in favor of IC [22, 23, 25, 27]. On the contrary, the last 
actualization of the MACH-NC analysis with more than 100 trials and 19,248 patients showed in a direct comparison between IC and CCR that OS was significantly better with CCR (HR 0.84 [95\%CI 0.74-0.95], $\mathrm{p}=0.0007$ ) [28]. But, the major issue of these meta-analyses is the type of IC that include non-platin-based chemotherapy, platin-based chemotherapy without docetaxel and TPF. Today we have no meta-analysis focusing only on trials of IC by TPF and again no definitive conclusion can be drawn.

\section{5 | LESS TOXIC INDUCTION CHEMOTHERAPY ATTEMPTS AND BETTER SELECTION:}

Two major issues limit IC when compared with CCR: it could compromise the following CCR and its own toxicity (7\% of death rate reported in one phase III study [19]). None but one of the five phase III mentioned above use standard potentiation by three cisplatin $100 \mathrm{mg} / \mathrm{m} 2$ after induction. It showed that if $80.5 \%$ of the patients of the CCR arm received the three cycles of cisplatin, they were only 59.4\% in the TPF arm [20]. Another study showed that only $22 \%$ of the patients were able to be treated by CCR with cisplatin $>200 \mathrm{mg} / \mathrm{m} 2$ after three cycles TPF [29]. That's why new less toxic schedules were explored. Since modified TPF (docetaxel and cisplatin at $40 \mathrm{mg} / \mathrm{m} 2$ each on day 1 , leucovorin $400 \mathrm{mg} / \mathrm{m} 2$ followed by a bolus of fluorouracil at $400 \mathrm{mg} / \mathrm{m} 2$ then $1000 \mathrm{mg} / \mathrm{m} 2 /$ day, day 1 -day 2, every two weeks) increased OS with less toxicity in gastric cancer compared to TPF, it was tested in HNSCC for patients unfit for TPF (PS>1, Age>70 years, cardiac failure, high loss of weight...) in a retrospective study [30]. In this frail population, only $8 \%$ febrile neutropenia and $4 \%$ death was observed and modified TPF allowed $83 \%$ responses and $81 \%$ of patients could be irradiated. A randomized study of the GORTEC is currently evaluating modified TPF compared to TPF for fit patients as IC. 
Another small monocentric retrospective study evaluated dose-dense modified TPF in 11 patients: docetaxel 40mg/m2, cisplatin 40mg/m2 or carboplatin AUC2 and fluorouracil (400mg/m2 bolus then $1000 \mathrm{mg} / \mathrm{m} 2$ in $96 \mathrm{~h}$ ), bi-monthly [31]. One patient had febrile neutropenia, no grade 3-4 gastrointestinal toxicity was reported and response rate reached $90 \%$ (30\% complete response).

A retrospective study compared 53 patients treated in a single institution by carboplatin AUC2 and paclitaxel 135mg/m2 every seven days for six weeks (CP) to 90 treated by TPF [32]. In multivariate analysis, locoregional control was better in the CP arm (HR 0.27; $\mathrm{p}=0.04)$, but not PFS $(\mathrm{p}=0.15)$. Renal toxicity was higher with the TPF arm and neutropenia occurred more often with CP.

These studies are too small to conclude but suggest that new modalities of IC are possible in order to decrease toxicity. The challenge is to assess if efficacy could be maintained. Since IC could be a treatment of choice for a large number of patients, a current challenge is to select these patients. A phase II tried to modify TPF and quickly select patients with a LAHNSCC who will benefit from it [33]. The split-dose TPF was a 3-week cycle with docetaxel $30 \mathrm{mg} / \mathrm{m} 2$, cisplatin $40 \mathrm{mg} / \mathrm{m} 2$, fluorouracil $2000 \mathrm{mg} / \mathrm{m} 2$ during $24 \mathrm{~h}$ at days 1 and 8. It was administered to 54 patients with locally advanced and resectable cancer of the oral cavity or oropharynx. In responders (radiological response $>30 \%, 70 \%$ of patients), IC was continued with an additional two cycles more before surgery and CCR. In non-responders, surgery was immediately performed before CCR. All the patients benefited from surgery and major radiotherapy protocol deviations did not occur. As expected, 24 months PFS and OS were higher in responders ( $88.5 \%$ vs $60.6 \%$ and $97.3 \%$ vs $73.7 \%$ respectively). Fluorouracil is probably the less efficient drug in TPF and has an important toxicity, so various schedules were developed without it.

A randomized, multicenter phase II study [34] enrolled 92 patients with LAHNSCC to receive 
three cycles of docetaxel and cisplatin with or without cetuximab (TP and TPE) as induction chemotherapy. Patients in the TPE arm received CCR with cetuximab and cisplatin whereas patients in the TP arm received cisplatin alone. In intention-to-treat analysis, the 3-year OS was not increased by cetuximab ( $88 \%$ vs $74 \%, \mathrm{p}=0.31$ ), possibly because cetuximab was responsible for a diminished treatment completion (67\% vs $77 \%)$. In per protocol analysis (IC + CCR completed, $67 \%$ in the TPE arm vs 77\%), the 3-year OS was significantly higher with cetuximab (94\% vs $73 \%, \mathrm{p}=0.045)$.

A single arm essay using the same IC with TPE and CCR with cisplatin and cetuximab [35] had similar results: 3-year PFS 70\% (95\%CI 53\%-82\%) and 3-year OS 74\%. Again, toxicity was important with frequent grade 3/4 toxicities, including febrile neutropenia (10\%), mucositis (54\%), dysphagia (48\%), and hypomagnesemia (39\%). So replacing fluorouracil by cetuximab is toxic and does not show clear evidence of superiority.

A Phase II trial [36] included 47 patients with LAHNSCC to receive bi-monthly six cycles of paclitaxel $135 \mathrm{mg} / \mathrm{m} 2$ and carboplatin (AUC2) with cetuximab. CCR was potentiated with cisplatin. The 3-year PFS and OS rates were 87\% (95\%CI 78\%-97\%) and 91\% (95\%CI 84\%99\%), respectively. Excepted for mucositis (77\% grade 3-4), skin rash (45\% grade 3-4) and $21 \%$ non-febrile neutropenia, this scheme was well tolerated and a majority of the patients completed induction as planned per protocol.

Two other phase II studies with 63 and 30 patients confirmed that the combination of carboplatin, paclitaxel and cetuximab seems safe and promising [37],[38].

PET-scans could be an interesting option to select responders to IC. A French prospective essay evaluated the metabolic response after two cycles of TPF in 15 patients with nonsurgical LAHNSCC. FDG PET-scans were performed before and after two cycles of TPF, and SUV-max comparison was performed between the two exams. Median PFS was 18.9 months for metabolic responders (decrease of SUV-max >25\%) and 10.2 months for 
metabolic non-responders $(\mathrm{p}=0,0014)$ [39]. Those results were confirmed in a 26 patients cohort with PET-scan evaluation after one TPF course [40]. Early identification of nonresponders would possibly have avoided ineffective treatment and many unnecessary adverse effects.

So a less toxic schedule and a better and earlier assessment of effectiveness of IC are probably a promising way and deserve additional investigations.

\section{6 | CAN TPF BE INTENSIFIED?}

Despite its toxicity, some studies tried to intensify TPF. A first phase II trial in 50 patients added weekly cetuximab to TPF (C-TPF) for four cycles [41]. Response rate was similar to TPF at $86 \%$ (95\% CI: 73-94) but toxicity was highly increased with febrile neutropenia (24\%), grade 3-4 diarrhea (20\%) and grade 3-4 mucositis (14\%). On the contrary, another study in Taiwan suggested on the contrary the feasibility of two C-TPF, with similar grade 34 leucopenia (26\% and $28 \%$ for TPF and C-TPF, respectively). Patients were clearly different from western countries (young, non-drinker, non-smoker) [42].

A German study compared C-TPF to TPF but, due to the toxicity, the protocol was amended to suppress fluorouracil and then to compare C-TP to TP in 173 patients [43]. No significant difference was observed between the two arms in 2-year OS (overall or with functional larynx). Since the standard is TPF no conclusion can be drawn.

Because of the high toxicity of C-TPF, docetaxel was replaced by nabpaclitaxel $\left(100 \mathrm{mg} / \mathrm{m}^{2}\right)$ and fluorouracil shortened at day 1 to 3 in a phase II trial in 30 patients [44]. This promising 
schedule showed 53\% complete response and did not adversely affect delivery of definitive CCR $\left(81 \%\right.$ of patients did receive three cycles of cisplatin $\left.100 \mathrm{mg} / \mathrm{m}^{2}\right)$.

Since immunotherapy with anti-PD1/PDL1 demonstrated efficacy in recurrent HNSCC with an excellent tolerability, these checkpoint inhibitors are currently tested in combination with TPF and can provide a new type of intensification in induction.

\section{7 | WHICH POTENTIATION AFTER INDUCTION?}

To this day, there is no standard approach for radiotherapy after IC: on its own? With cisplatin? With cetuximab?

A French phase II study tried to answer this by comparing radiotherapy (70Gy) with concurrent cisplatin $\mathrm{q} 3 \mathrm{w}$ with concurrent cetuximab after three TPF for organ preservation (stage III or IV larynx/hypopharynx) [45]. The primary end point was larynx preservation at three months, and there was no significant difference (95\% and $93 \%$, respectively), and it was similar for OS at 18 months ( $92 \%$ and $89 \%$, respectively). Local failures were more numerous in the cetuximab group. Radiotherapy with cisplatin was more toxic since only $42 \%$ of patients received the three planned cycles whereas $71 \%$ of the patients in the cetuximab group received the seven planned injections.

The interim analysis of a phase III study with the same approach was presented with the same approach [46]: 519 patients with inoperable stage III/IV HNSCC received TPF. If it was tolerated and there was no progression, they were randomized (407) to receive potentiation by either cisplatin or cetuximab. Because of the excellent results of IC, this trial didn't reach sufficient event rates and only interim data were presented. In intention-to-treat analysis, median OS was 42.2 months (95\%CI 33.7-52.4). There was a non-significant trend for cisplatin: 63.6 months (95\%CI 43.6-77.5) vs 47.1 months (95\%CI 33.7-NA) for OS (p=1.17) and 37 months (95\%CI 23-62.9) vs 20,7 months (95\%CI 15.3-31.1) for PFS ( $\mathrm{p}=1.20)$. More 
time is needed to see if this trend in favor of cisplatin is confirmed and becomes significant.

\section{8 | INDUCTION AND HUMAN PAPILLOMA VIRUS (HPV)}

In Europe, almost $40 \%$ of HNSCC are HPV related [47]. Several essays showed the higher chemosensitivity and radiosensitivity of HPV induced HNSCC [48].

In a retrospective subset analysis of an EORTC phase III essay for IC (PF versus TPF), 14\% of evaluable samples were p16+ and $25 \%$ were HPV-DNA+. The analysis showed no statistical evidence of predictive value of HPV/p16 status either for PFS $(\mathrm{P}=0.287)$ or OS $(P=0.118)$. Those results do not justify deintensifying TPF for PF in HPV related HNSCC [49].

A subset analysis of the American National Cancer Database with almost 15,000 patients with oropharyngeal cancer was conducted to evaluate HPV status impact. HPV status was known in $35 \%$ of patients, and it was positive for $55 \%$ of them. HPV-positivity was associated with a better 3-year OS with a HR of $0.46(95 \%$ CI $0.35-0.60, \mathrm{p}<0.001)$. There was no statistical difference between IC and CCR with HPV-positive patients (HR 0.96; 95\% CI 0.72-1.27; $\mathrm{p}=0.761$ ). However, when further restricting the cohort to high risk (T4 and/or N3 disease) HPV-negative tumors ( $n=219)$, IC treatment was significantly associated with higher 3-year OS (HR 0.63; 95\% CI 0.0-1.0; p=0.048). Further analyses is needed [50]. ECOG 1308 trial[51] suggested that tumor response rate to IC with three cycles of cisplatin, paclitaxel and cetuximab could be used to select patients for de-escalation radiation dose in HPV related HNSCC. Patient with a complete response rate after three cycles of IC (70\% of them) received CCR with 54Gy potentiated with weekly cetuximab, those without a complete response received 69,3Gy with weekly cetuximab. Indeed, outcomes where excellent for responders, with 2-year PFS and OS rates of $80 \%$ and 94\%, respectively. Moreover, radiation 
dose reduction improved swallowing and nutritional status.

\section{9 | CONCLUSION}

Induction chemotherapy has several aims for LAHNSCC. It can decrease the tumor volume in order to make a tumor resectable. Moreover, its goal is to eradicate micrometastases and reduce locoregional failure. The standard treatment for induction is TPF. When a treatment for preservation of laryngeal function is propounded, chemotherapy with TPF has shown its superiority with a high level of evidence. Outside larynx preservation, CCR is the standard and $\mathrm{IC}+\mathrm{CCR}$ remains an option. But, in direct comparisons, no study definitively concludes to the superiority of any strategy and IC seems to be non-inferior to exclusive CCR. Metaanalysis cannot draw any definitive answer because none is focused on trials using TPF for IC. Further evaluations are needed and today IC is a reliable option [52],[53] Because of the high toxicity of IC, additional investigations are necessary to design less toxic schedules having the same efficacy. Various ways are explored to identify non-responders and spare them from accrued toxicities and an early assessment of efficacy by PET-scan is one of them. On the contrary, attempts to intensify TPF with cetuximab in order to increase efficacy were highly toxic. Promising schemes with nab-paclitaxel or immunotherapy should increase the choice of TPF for a selected population.

After a treatment by IC, essays didn't highlight any superiority in using cetuximab or cisplatin for CCR, even if CCR with cetuximab seems to be well tolerated. 


\section{REFERENCES :}

[1] Parkin DM, Bray F, Ferlay J, Pisani P. Global cancer statistics, 2002. CA Cancer J Clin 2005; 55(2):74-108.

[2] Ensley JF, Jacobs JR, Weaver A et al. Correlation between response to cisplatinumcombination chemotherapy and subsequent radiotherapy in previously untreated patients with advanced squamous cell cancers of the head and neck. Cancer 1984; 54(5):811814.

[3] Forastiere AA, Goepfert H, Maor M et al. Concurrent Chemotherapy and Radiotherapy for Organ Preservation in Advanced Laryngeal Cancer. New England Journal of Medicine 2003; 349(22):2091-2098.

[4] Gorphe P, Matias M, Blanchard P et al. Outcomes following laryngectomy refusal after insufficient response to induction chemotherapy. Laryngoscope 2017; 127(8):17911796.

[5] Pignon J-P, le Maître A, Maillard E et al. Meta-analysis of chemotherapy in head and neck cancer (MACH-NC): an update on 93 randomised trials and 17,346 patients. Radiother Oncol 2009; 92(1):4-14.

[6] Vermorken JB, Remenar E, van Herpen C et al. Standard cisplatin/infusional 5fluorouracil (PF) vs docetaxel (T) plus PF (TPF) as neoadjuvant chemotherapy for nonresectable locally advanced squamous cell carcinoma of the head andneck (LASCCHN): a phase III trial of the EORTC Head and Neck Cancer Group (EORTC \#24971). JCO 2004; 22(14_suppl):5508-5508.

[7] Posner MR, Hershock DM, Blajman CR et al. Cisplatin and fluorouracil alone or with docetaxel in head and neck cancer. N. Engl. J. Med. 2007; 357(17):1705-1715.

[8] Lorch JH, Goloubeva O, Haddad RI et al. Induction chemotherapy with cisplatin and fluorouracil alone or in combination with docetaxel in locally advanced squamous-cell cancer of the head and neck: long-term results of the TAX 324 randomised phase 3 trial. Lancet Oncol. 2011; 12(2):153-159.

[9] Blanchard P, Bourhis J, Lacas B et al. Taxane-cisplatin-fluorouracil as induction chemotherapy in locally advanced head and neck cancers: an individual patient data meta-analysis of the meta-analysis of chemotherapy in head and neck cancer group. J. Clin. Oncol. 2013; 31(23):2854-2860.

[10] Group* TD of VALCS. Induction Chemotherapy plus Radiation Compared with Surgery plus Radiation in Patients with Advanced Laryngeal Cancer. New England Journal of Medicine 1991; 324(24):1685-1690.

[11] Lefebvre J-L, Andry G, Chevalier D et al. Laryngeal preservation with induction chemotherapy for hypopharyngeal squamous cell carcinoma: 10-year results of EORTC trial 24891. Ann. Oncol. 2012; 23(10):2708-2714.

[12] Forastiere AA, Zhang Q, Weber RS et al. Long-Term Results of RTOG 91-11: A Comparison of Three Nonsurgical Treatment Strategies to Preserve the Larynx in Patients With Locally Advanced Larynx Cancer. J Clin Oncol 2013; 31(7):845-852.

[13] Pointreau Y, Garaud P, Chapet S et al. Randomized trial of induction chemotherapy with cisplatin and 5-fluorouracil with or without docetaxel for larynx preservation. J. Natl. Cancer Inst. 2009; 101(7):498-506. 
[14] Posner MR, Norris CM, Wirth LJ et al. Sequential therapy for the locally advanced larynx and hypopharynx cancer subgroup in TAX 324: survival, surgery, and organ preservation. Ann. Oncol. 2009; 20(5):921-927.

[15] Trial of Laryngeal Preservation Comparing Induced CT Followed by RT vs CT Concomitant to RT - Full Text View - ClinicalTrials.gov. [https://clinicaltrials.gov/ct2/show/NCT03340896].

[16] Cohen EEW, Karrison TG, Kocherginsky M et al. Phase III randomized trial of induction chemotherapy in patients with N2 or N3 locally advanced head and neck cancer. J. Clin. Oncol. 2014; 32(25):2735-2743.

[17] Haddad R, O'Neill A, Rabinowits G et al. Induction chemotherapy followed by concurrent chemoradiotherapy (sequential chemoradiotherapy) versus concurrent chemoradiotherapy alone in locally advanced head and neck cancer (PARADIGM): a randomised phase 3 trial. Lancet Oncol. 2013; 14(3):257-264.

[18] Izawa N, Onozawa Y, Hikosaka T et al. Efficacy and feasibility of docetaxel, cisplatin, and 5-fluorouracil induction chemotherapy for locally advanced head and neck squamous cell carcinoma classified as clinical nodal stage N2c, N3, or N2b with supraclavicular lymph node metastases. Int. J. Clin. Oncol. 2015; 20(3):455-462.

[19] Geoffrois L, Martin L, Garaud P et al. Induction docetaxel platinum 5-FU (TPF) followed by cetuximab-radiotherapy (cetux-RT) versus concurrent chemo-radiotherapy (CT/RT) in patients with N2b/c-N3 non operated stage III-IV squamous cell cancer of the head and neck (SCCHN): Results of the GORTEC 2007-02 phase III randomized trial. JCO 2016; 34(15_suppl):6000-6000.

[20] Hitt R, Grau JJ, López-Pousa A et al. A randomized phase III trial comparing induction chemotherapy followed by chemoradiotherapy versus chemoradiotherapy alone as treatment of unresectable head and neck cancer. Ann. Oncol. 2014; 25(1):216-225.

[21] Ghi MG, Paccagnella A, Ferrari D et al. Induction TPF followed by concomitant treatment versus concomitant treatment alone in locally advanced head and neck cancer. A phase II-III trial. Ann. Oncol. 2017; 28(9):2206-2212.

[22] Ma J, Liu Y, Yang X et al. Induction chemotherapy in patients with resectable head and neck squamous cell carcinoma: a meta-analysis. World J Surg Oncol 2013; 11:67.

[23] Ma J, Liu Y, Huang X-L et al. Induction chemotherapy decreases the rate of distant metastasis in patients with head and neck squamous cell carcinoma but does not improve survival or locoregional control: A meta-analysis. Oral Oncology 2012; 48(11):10761084.

[24] Zhang L, Jiang N, Shi Y et al. Induction chemotherapy with concurrent chemoradiotherapy versus concurrent chemoradiotherapy for locally advanced squamous cell carcinoma of head and neck: a meta-analysis. Scientific Reports 2015; 5:10798.

[25] Vidal L, Ben Aharon I, Limon D et al. Role of Induction Chemotherapy Prior to Chemoradiation in Head and Neck Squamous Cell Cancer-Systematic Review and Metaanalysis. Cancer J 2017; 23(2):79-83.

[26] Kim R, Hahn S, Shin J et al. The Effect of Induction Chemotherapy Using Docetaxel, Cisplatin, and Fluorouracil on Survival in Locally Advanced Head and Neck Squamous Cell Carcinoma: A Meta-Analysis. Cancer Res Treat 2016; 48(3):907-916.

[27] Budach W, Bölke E, Kammers K et al. Induction chemotherapy followed by concurrent radio-chemotherapy versus concurrent radio-chemotherapy alone as treatment of locally advanced squamous cell carcinoma of the head and neck (HNSCC): A meta-analysis of randomized trials. Radiother Oncol 2016; 118(2):238-243.

[28] Blanchard P, Landais C, Petit C et al. Meta-analysis of chemotherapy in head and neck cancer (MACH-NC): An update on 100 randomized trials and 19,248 patients, on behalf of MACH-NC group. Ann Oncol 2016. doi:10.1093/annonc/mdw376.02. 
[29] Driessen CML, de Boer JP, Gelderblom H et al. Induction chemotherapy with docetaxel/cisplatin/5-fluorouracil followed by randomization to two cisplatin-based concomitant chemoradiotherapy schedules in patients with locally advanced head and neck cancer (CONDOR study) (Dutch Head and Neck Society 08-01): A randomized phase II study. Eur. J. Cancer 2016; 52:77-84.

[30] Fayette J, Fontaine-Delaruelle C, Ambrun A et al. Neoadjuvant modified TPF (docetaxel, cisplatin, fluorouracil) for patients unfit to standard TPF in locally advanced head and neck squamous cell carcinoma: a study of 48 patients. Oncotarget 2016; 7(24):37297-37304.

[31] Yossi S, Linot B, Peyraga G et al. Feasibility and safety of dose-dense modified docetaxel-cisplatin or carboplatin and 5-fluorouracil regimen (mTPF) in locally advanced or metastatic head and neck cancers: a retrospective monocentric study. Int. J. Clin. Oncol. 2015; 20(6):1086-1092.

[32] Herman LC, Chen L, Garnett A et al. Comparison of carboplatin-paclitaxel to docetaxelcisplatin-5-flurouracil induction chemotherapy followed by concurrent chemoradiation for locally advanced head and neck cancer. Oral Oncol. 2014; 50(1):52-58.

[33] Inhestern J, Schmalenberg H, Dietz A et al. A two-arm multicenter phase II trial of one cycle chemoselection split-dose docetaxel, cisplatin and 5-fluorouracil (TPF) induction chemotherapy before two cycles of split TPF followed by curative surgery combined with postoperative radiotherapy in patients with locally advanced oral and oropharyngeal squamous cell cancer (TISOC-1). Ann. Oncol. 2017; 28(8):1917-1922.

[34] Lee K-W, Koh Y, Kim S-B et al. A Randomized, Multicenter, Phase II Study of Cetuximab With Docetaxel and Cisplatin as Induction Chemotherapy in Unresectable, Locally Advanced Head and Neck Cancer. Oncologist 2015; 20(10):1119-1120.

[35] Argiris A, Heron DE, Smith RP et al. Induction Docetaxel, Cisplatin, and Cetuximab Followed by Concurrent Radiotherapy, Cisplatin, and Cetuximab and Maintenance Cetuximab in Patients With Locally Advanced Head and Neck Cancer. J Clin Oncol 2010; 28(36):5294-5300.

[36] Kies MS, Holsinger FC, Lee JJ et al. Induction chemotherapy and cetuximab for locally advanced squamous cell carcinoma of the head and neck: results from a phase II prospective trial. J. Clin. Oncol. 2010; 28(1):8-14.

[37] Wanebo HJ, Lee J, Burtness BA et al. Induction cetuximab, paclitaxel, and carboplatin followed by chemoradiation with cetuximab, paclitaxel, and carboplatin for stage III/IV head and neck squamous cancer: a phase II ECOG-ACRIN trial (E2303). Ann. Oncol. 2014; 25(10):2036-2041.

[38] Bauman J, Langer C, Quon H et al. Induction chemotherapy with cetuximab, carboplatin and paclitaxel for the treatment of locally advanced squamous cell carcinoma of the head and neck. Exp Ther Med 2013; 5(4):1247-1253.

[39] Abgral R, Le Roux P-Y, Keromnes N et al. Early prediction of survival following induction chemotherapy with DCF (docetaxel, cisplatin, 5-fluorouracil) using FDG PET/CT imaging in patients with locally advanced head and neck squamous cell carcinoma. Eur. J. Nucl. Med. Mol. Imaging 2012; 39(12):1839-1847.

[40] Popovtzer A, Burnstein H, Stemmer S et al. Phase II organ-preservation trial: Concurrent cisplatin and radiotherapy for advanced laryngeal cancer after response to docetaxel, cisplatin, and 5-fluorouracil-based induction chemotherapy. Head Neck 2017; 39(2):227-233.

[41] Mesia R, Vázquez S, Grau JJ et al. A single-arm phase II trial to evaluate the combination of cetuximab plus docetaxel, cisplatin, and 5-fluorouracil (TPF) as induction chemotherapy (IC) in patients (pts) with unresectable SCCHN. JCO 2009; 27(15_suppl):6015-6015. 
[42] Chang PM-H, Lu H-J, Wang L-W et al. Effectiveness of incorporating cetuximab into docetaxel/cisplatin/fluorouracil induction chemotherapy and chemoradiotherapy for inoperable squamous cell carcinoma of the oral cavity: A phase II study. Head Neck 2017; 39(7):1333-1342.

[43] Dietz A, Wichmann G, Flentje M et al. Final results of the randomized phase II DeLOSII trial: Induction chemotherapy (IC) followed by radiotherapy (R) vs. cetuximab (E) plus IC and $\mathrm{R}$ for functional larynx preservation in resectable laryngeal and hypopharyngeal cancer (LHSCC). JCO 2016; 34(15_suppl):6025-6025.

[44] Adkins D, Ley J, Michel L et al. nab-Paclitaxel, cisplatin, and 5-fluorouracil followed by concurrent cisplatin and radiation for head and neck squamous cell carcinoma. Oral Oncol. 2016; 61:1-7.

[45] Lefebvre JL, Pointreau Y, Rolland F et al. Induction chemotherapy followed by either chemoradiotherapy or bioradiotherapy for larynx preservation: the TREMPLIN randomized phase II study. J. Clin. Oncol. 2013; 31(7):853-859.

[46] Hitt R, Mesia R, Grau JJ et al. Randomized phase III trial of induction chemotherapy (ICT) with docetaxel-cisplatin-5fluorouracil (DCF) followed by cisplatin-radiotherapy (CRT) or cetuximab-radiotherapy (CetRT) in patients (pts) with locally advanced unresectable head and neck cancer (LAUHNC). JCO 2016; 34(15_suppl):6001-6001.

[47] Abogunrin S, Di Tanna GL, Keeping S et al. Prevalence of human papillomavirus in head and neck cancers in European populations: a meta-analysis. BMC Cancer 2014; 14:968.

[48] Fakhry C, Gillison ML. Clinical implications of human papillomavirus in head and neck cancers. J. Clin. Oncol. 2006; 24(17):2606-2611.

[49] Psyrri A, Fortpied C, Koutsodontis G et al. Evaluation of the impact of tumor HPV status on outcome in patients with locally advanced unresectable head and neck squamous cell carcinoma (HNSCC) receiving cisplatin, 5-fluorouracil with or without docetaxel: a subset analysis of EORTC 24971 study. Ann. Oncol. 2017; 28(9):22132218.

[50] Sher DJ, Schwartz DL, Nedzi L et al. Comparative effectiveness of induction chemotherapy for oropharyngeal squamous cell carcinoma: A population-based analysis. Oral Oncology 2016; 54:58-67.

[51] Marur S, Li S, Cmelak AJ et al. E1308: Phase II Trial of Induction Chemotherapy Followed by Reduced-Dose Radiation and Weekly Cetuximab in Patients With HPVAssociated Resectable Squamous Cell Carcinoma of the Oropharynx- ECOG-ACRIN Cancer Research Group. JCO 2016; 35(5):490-497.

[52] Adelstein D, Gillison ML, Pfister DG et al. NCCN Guidelines Insights: Head and Neck Cancers, Version 2.2017. J Natl Compr Canc Netw 2017; 15(6):761-770.

[53] Beitler JJ, Quon H, Jones CU et al. ACR Appropriateness Criteria(®) Locoregional therapy for resectable oropharyngeal squamous cell carcinomas. Head Neck 2016; 38(9):1299-1309. 


\section{0-year results of EORTC trial}

$100 \%$

$90 \%$

$80 \%$

$70 \%$

$60 \%$

$50 \%$

$40 \%$

$30 \%$

$20 \%$

$10 \%$

$0 \%$

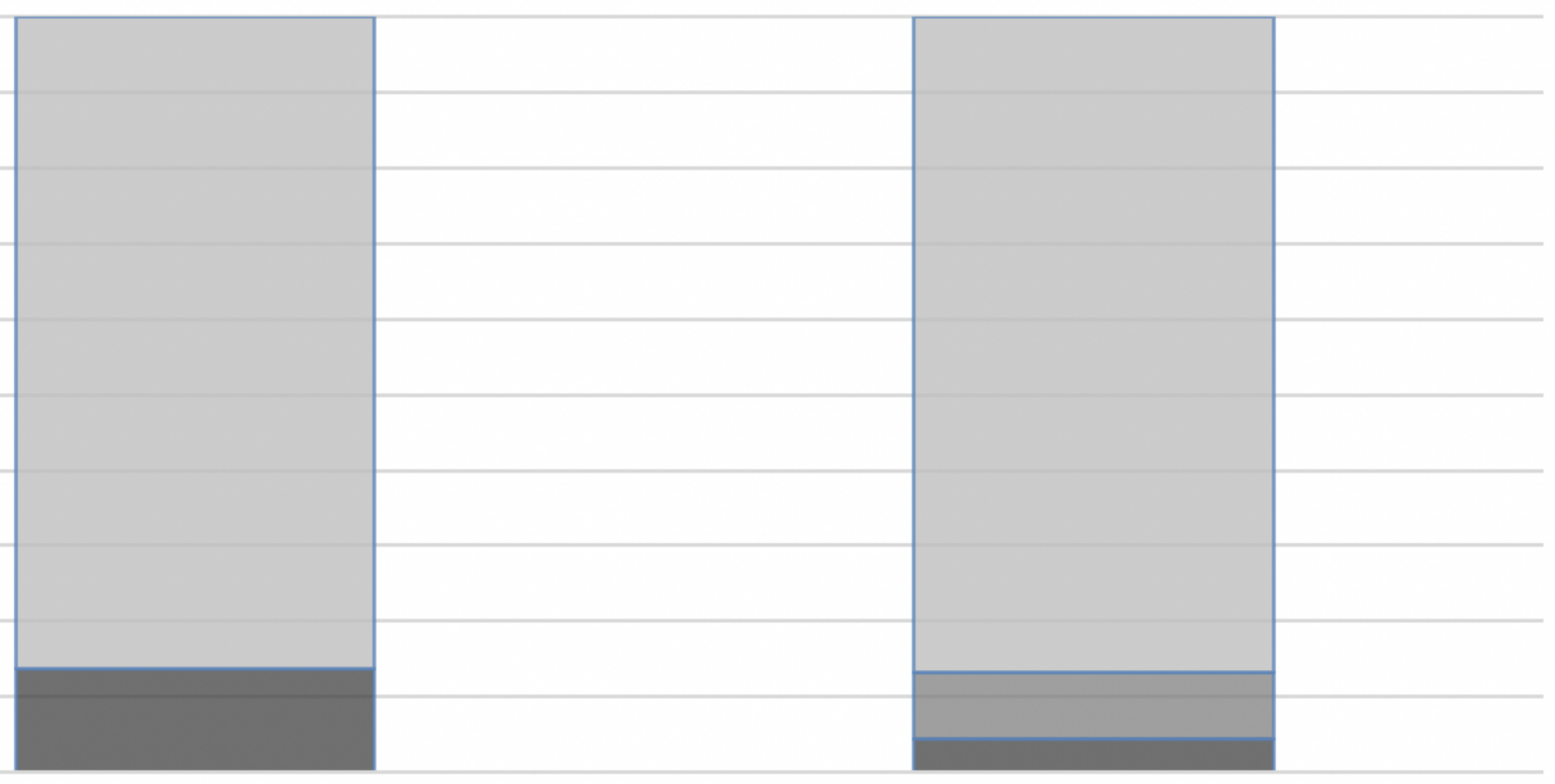

Surgery arm

IC+RT arm

- Survival without functional larynx

$\square$ Survival with functional larynx

Death 


\section{0-year results of RTOG 91-11 trial}

$100 \%$
$90 \%$
$80 \%$
$70 \%$
$60 \%$
$50 \%$
$40 \%$
$30 \%$
$20 \%$
$10 \%$
$0 \%$

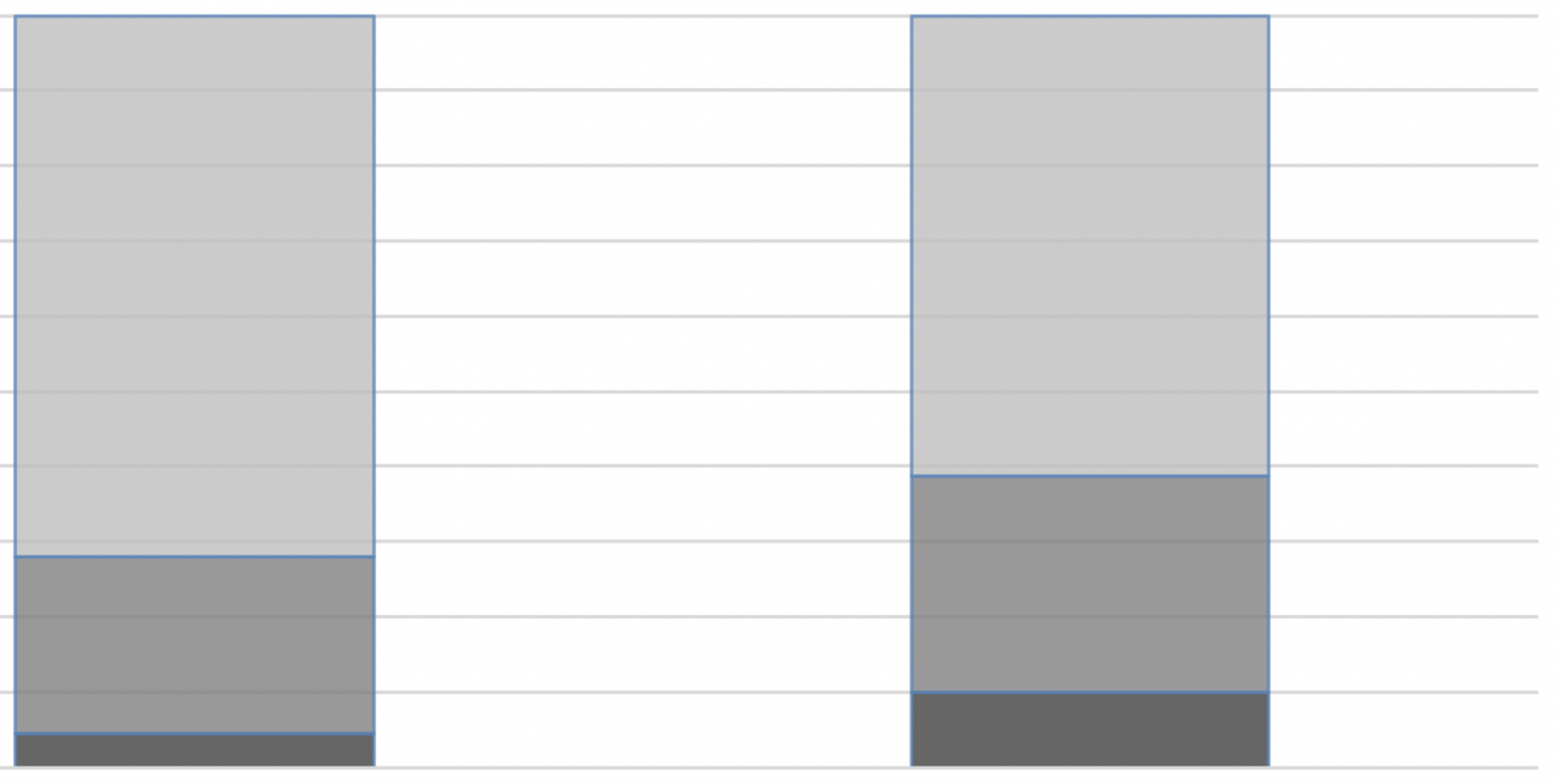

CCR (RT+cisplatine $100 \mathrm{mg} / \mathrm{m} 2)$ arm

IC(PF)+RT arm

- Survival with laryngectomy

$\square$ Laryngectomy free surviva

$\square$ Death 
Table 1: Direct comparisons in phase III trials

\begin{tabular}{|c|c|c|c|c|}
\hline Trial & Trial scheme & Population/follow-up & Results & Bias and weaknesses \\
\hline DeCIDE trial ${ }^{16}$ & $\begin{array}{l}\text { TPF + CCR (with } \\
\text { fluorouracil, docetaxel } \\
\text { and hydroxyurea) versus } \\
\text { same CCR }\end{array}$ & $\begin{array}{l}-285 \text { patients with N2 } \\
\text { and N3 HNSCC } \\
-30 \text { months follow-up }\end{array}$ & $\begin{array}{l}\text { No statistically } \\
\text { significant difference in } \\
\text { OS (HR, 0.91; 95\% CI, } \\
0.59-1.41) \text {, in favor of } \\
\text { IC } \\
\text { Strong trend in OS for } \\
\text { high risk tumors (N2c } \\
\text { and N3). }\end{array}$ & $\begin{array}{l}\text { Lack of power: } \\
\text {-only } 285 / 400 \text { patients } \\
\text { included } \\
\text {-OS higher than expected }\end{array}$ \\
\hline PARADIGM trial ${ }^{17}$ & $\begin{array}{l}\text { TPF + CCR (with } \\
\text { carboplatin or } \\
\text { docetaxel) versus CCR } \\
\text { (with two cycles of } \\
\text { cisplatin } 100 \mathrm{mg} / \mathrm{m}^{2} \text { ) }\end{array}$ & $\begin{array}{l}145 \text { patients with high } \\
\text { risk HNSCC: } \\
\text {-stage III or IV, } \\
\text {-N2 or N3 (except N2 } \\
\text { T1). } \\
\text {-three years follow-up }\end{array}$ & $\begin{array}{l}\text { No statistically } \\
\text { significant difference in } \\
\text { OS (HR, } 1.09 ; 95 \% \text { CI } \\
0.59-2.03) \text {, in favor of } \\
\text { IC }\end{array}$ & $\begin{array}{l}\text { Lack of power: } \\
\text { - only } 145 / 300 \text { patients } \\
\text { included } \\
\text {-OS was higher than } \\
\text { expected in the control } \\
\text { arm }\end{array}$ \\
\hline $\begin{array}{l}\text { GORTEC 2007-02 } \\
\text { trial }^{18}\end{array}$ & $\begin{array}{l}\text { TPF + CCR (with } \\
\text { cetuximab) versus CCR } \\
\text { (three cycles of } \\
\text { carboplatin }+ \\
\text { fluorouracil) }\end{array}$ & $\begin{array}{l}370 \text { patients with high } \\
\text { risk HNSCC: } \\
\text {-stage III or IV } \\
\text {-N2b/c and N3 } \\
-31 \text { months follow-up }\end{array}$ & $\begin{array}{l}\text {-No statistically } \\
\text { significant differences } \\
\text { in PFS and OS (HR, } \\
1.10 ; 95 \% \text { CI 0.84-1.45) } \\
\text { in favor of CCR } \\
\text {-Higher distant free } \\
\text { metastasis survival in } \\
\text { TPF arm (HR, 0.62; } \\
\text { 95\% CI 0.40-0.95) }\end{array}$ & $\begin{array}{l}\text { CCR scheme was not a } \\
\text { standard (carboplatin }+ \\
\text { fluorouracil) }\end{array}$ \\
\hline${\text { TTCC } \text { trial }^{19}}^{19}$ & $\begin{array}{l}\text { TPF + CCR (three } \\
\text { cycles of cisplatin } 100 \\
\mathrm{mg} / \mathrm{m}^{2} \text { ) versus PF }+ \\
\text { CCR versus CCR alone }\end{array}$ & $\begin{array}{l}439 \text { patients with stage } \\
\text { III and IV HNSCC } \\
-24 \text { months follow-up }\end{array}$ & $\begin{array}{l}\text { - No statistically } \\
\text { significant differences } \\
\text { in PFS (14,6 months in } \\
\text { TPF+CCR; } 14,3 \text { months } \\
\text { in PF+CCR and } 13,8 \\
\text { months in CCR alone }\end{array}$ & $\begin{array}{l}\text {-Many patients where } \\
\text { ECOG } 1 \text { regarding to the } \\
\text { other trials. } \\
\text {-Many high-volume } \\
\text { tumors (T4) }\end{array}$ \\
\hline
\end{tabular}

